\title{
Keel Influence on the Added Wave Resistance for Yachts
}

\author{
by Marcos de Parahyba Campos*, Member
}

\author{
Tsugukiyo Hirayama**, Member
}

\begin{abstract}
Summary
Sailing yachts has been experienced extensively in the past years, generating very fast yachts. However, the search for speed has lead to very similar boats, with similar performance and, frequently, with poor behavior in rough water. The study of performance of sailing yacht in waves, experienced in heeled and yawed condition has been conducted, as well as the prediction of its motion in order to generate more data and provide tools to better design yachts for rough water. A deeper study of influence of the lateral force generated by the keel was done, testing the model with a normal fin keel and a pole keel (that did not generate lift). The free-running technique was applied in order to allow the model freedom for heeling and yawing. The resistance due to the attitude was obtained as an additional result. The conclusions are very interesting and intriguing and indicate the strong influence of the keel over the added resistance in waves, but the mechanism that rules that influence is not clear yet.
\end{abstract}

\section{Introduction}

The sailing yacht has been experiencing a quick performance development in the past few years. The researches have leaded the designers to push the design envelope to its limits, creating radical yachts with a performance unthinkable few years ago. Despite the quick increase in the final velocity of yacht, it looks like an upper limit was achieved, with the yachts presenting very similar performance. At the same time, the search for speed at any price resulted in yachts with very poor maneuverability and seaworthiness ${ }^{1)}$.

A better comprehension of the mechanism of added resistance in waves for yachts in heeled and yawed condition could solve both of these problems at once. At the same time it could provided the desired edge in the final velocity, it also could result in more seaworthy yachts, since a deeper study in the yacht motions would be necessary to explain the added resistance in waves.

The Yokohama National University has been work ing in these subjects for the past few years, proposing a new experimental set $-\mathrm{up}^{2 / 3)}$ that allows the yacht model to be experienced in waves using the free running technique. With such a technique, it is possible to run the

\footnotetext{
* Post Doctoral Fellow at IHI (Former student of YNU)

** Yokohama National University
}

Received 9th July 1999

Read at the Autumn meeting 18, 19th Nov. 1999 model in a coupled relation between the yaw and roll angle for a determined velocity with bow waves. Considering that the direction of wind and wind waves probably is coincident, the bow waves seems hard to be experienced for a sailing yacht. However, considering the swell, bow waves is quite possible to be experienced. The possibility to experience a yacht reproducing its actual sailing condition (heel and yaw angle determined by its stability characteristics as well as its velocity) opened new perspectives for a better understanding of the phenomena those rules the sailing of an yacht. These researchers found that the influence of appendages over the motion and, consequently, the added resistance in waves could be a new frontier for an improvement of overall performance of a sailing yacht.

In order to measure the influence of appendages over the added resistance, the model was experienced with two different sets of keel: one more conventional, consisting of a fin keel with a bulb attached in its low end; and the second one was a pole keel, with one sphere attached to the tip of a long cylinder. Despite being different, the keels confer to the model practically the same final stability characteristics. Since the canoe body, the rudder and the overall stability were quite similar, the results could be compared straightforward.

The experiments were conducted in upright condition and heeled-yawed condition in still water and in longcrested waves and the velocity range was chosen as a function of yacht performance in the upwind leg (around Froude number 0.30). To keep the analysis simple, only regular and transient waves were experi- 
enced and its incidence was parallel with the model path (bow waves).

It is the first time that comparisons of added resistance in waves between two different keels for an yacht model experienced in the free-running condition are published and the results are interesting and intriguing enough to justify the necessity of further research.

\section{Justification}

The main objective of this experiment was looking for answers that could explain the disagreement between the theoretical and experimental results found by the authors and published in the reference ${ }^{3)}$. The mathematical model utilized at that time was the Maruo's technique, including Fuji-Takahashi reflected wave effect, based in the New Strip Method, which did not allow the modeling of appendages. It was deduced that the influence of appendages over the motions and added resistance in waves could be playing a big whole in that difference.

The functions of the appendages are two:

- Provide the hydrodynamic lateral force that will equilibrate its aerodynamic counterpart.

- Keep the center of gravity as low as possible.

It can be concluded that the influence of appendage over the added resistance could be a result of its generated lateral force, that has a component pointing upwards in the heeled condition and/or the heave and pitch damping due to the projected horizontal area of bulb.

It was decided that substituting the conventional keel by a pole keel, consisting of a long cylinder with a sphere in its low end, could result in a structure that, due to its circular section, would not generate any lift and, at the same time, would keep the center of gravity low. The radius of gyration also could be kept close to

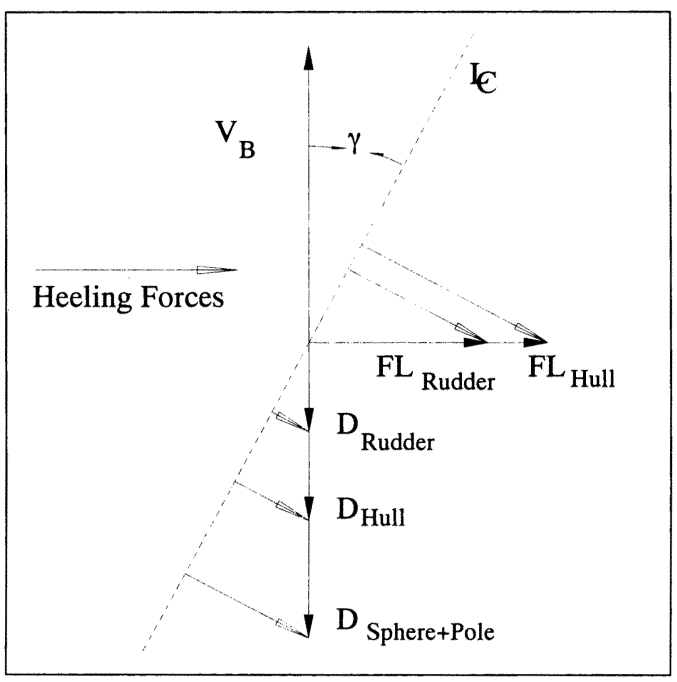

Fig. 1 Schematic representation of heeling forces. the value experimented with the fin keel, allowing the direct comparison of added resistance in waves and model motion for both sets of keels.

However, the lateral force generation is fundamental to equilibrate the model and, consequently, for the success of the free running method. Fortunately, due to the high drag developed by the pole keel and the drift angle, the component of keel drag perpendicular to the centerline of the model was large enough to equilibrate the towing force and also generate an appreciable heel angle without generating upwards components. In the Fig. 1 the drag and lateral forces are presented by solid arrow, while their projection square to the centerline is draw with empty arrows. Through the picture is easy to see that such a projection constitute the hydrodynamic heeling force, with combined with its aerodynamic counterpart will generate the coupled heeling moment.

However, this force was not sufficient to heel the model to the same values achieved with the fin keel and transversal arms with ballast had to be fitted transversally over the deck, in a similar way of that done in the Davidson's ${ }^{4)}$ technique.

\section{Model Configuration}

The model was a typical America's Cup IACC hull with a displacement body and fitted with a spade rudder and two kinds of keel :

- A fin keel, with a NACA wing profile and containing a bulb in its lower extremity.

- A pole keel (cylindrical) consisting of a cylinder with a sphere in its lower tip.

The body plan and buttock lines for both keels can be seen at the Fig. 3 where the same scale represents them.

The proposal of using a pole keel was based on the fact that, due to its circular geometry, such a structure would not generated lateral force

In order to compare the data for the fin keel

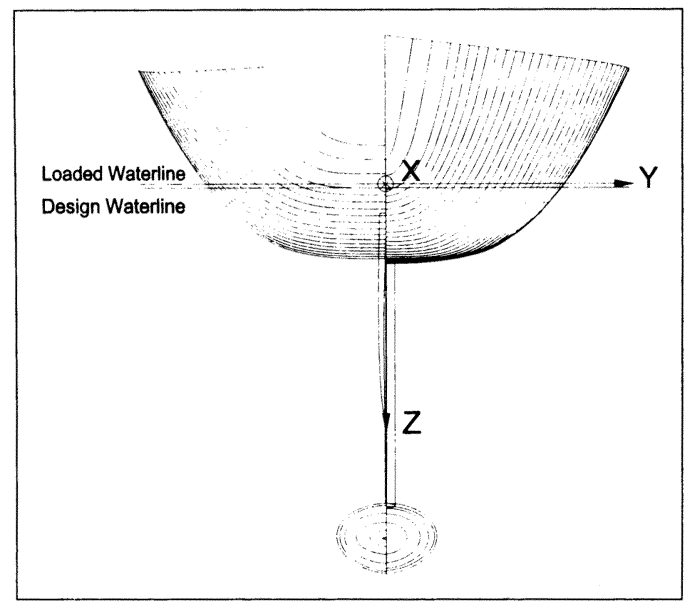

Fig. 2 Body plan with fin keel and bulb. 
configuration $^{233)}$ with the new data obtained for the pole keel, a careful design of the pole keel was done to keep the same overall stability characteristics of the yacht model, mainly the height of center of gravity and longitudinal radius of gyration. This was done in detrimen-

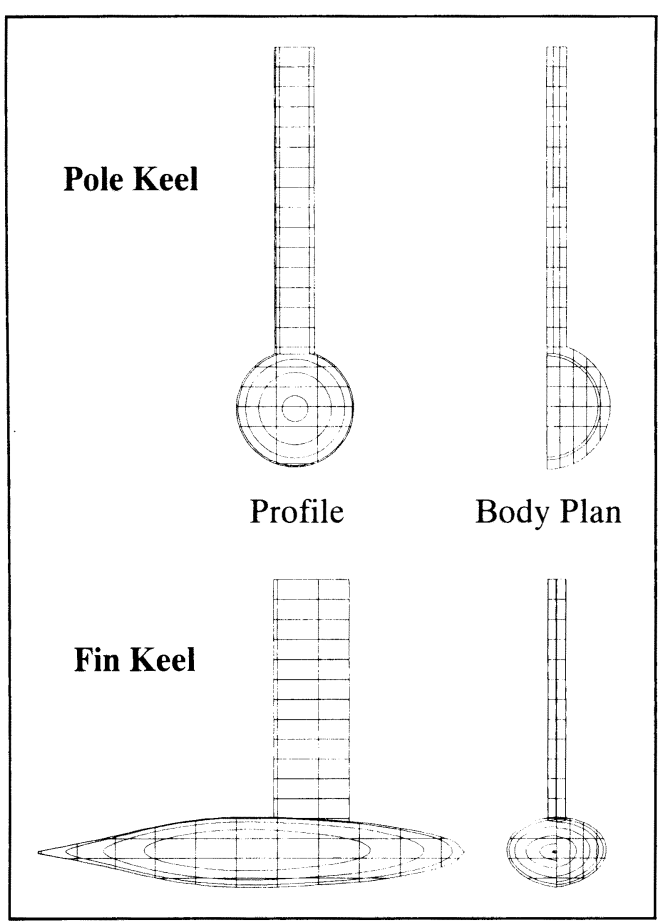

Fig. 3 Profile and body plans of the keels.

Table 1 Principals of Model

\begin{tabular}{|c|c|c|}
\hline \multicolumn{3}{|c|}{ Main Dimension of IACC Model A } \\
\hline Dimension & Fin Keel & Pole keel \\
\hline LOA & 2.791 & 2.791 \\
\hline LWL & 2.605 & 2.605 \\
\hline B & 0.732 & 0.732 \\
\hline BWL & 0.540 & 0.540 \\
\hline $\mathrm{T}_{\text {canoe body }}$ (loaded) & 0.122 & 0.122 \\
\hline $\mathrm{T}_{\text {total }}$ (loaded) & 0.585 & 0.585 \\
\hline $\mathrm{T}_{\text {canoe body }}($ design $)$ & 0.112 & 0.112 \\
\hline Displacement & 74.945 & 73.446 \\
\hline Wetted Surface $_{\text {canoe body }}$ & 1.117 & 1.093 \\
\hline Wetted Surface total & 1.482 & 1.438 \\
\hline Waterplane Area & 0.965 & 0.965 \\
\hline$C_{B}$ & 0.405 & 0.405 \\
\hline $\mathrm{C}_{\mathrm{M}}$ & 0.748 & 0.748 \\
\hline $\mathrm{C}_{\mathrm{P}}$ & 0.542 & 0.542 \\
\hline LCB & 1.370 & 1.370 \\
\hline $\mathrm{VCB}$ & 0.045 & 0.054 \\
\hline LCG & 1.370 & 1.370 \\
\hline $\mathrm{OG}$ & 0.096 & 0.067 \\
\hline Kyy (\% LOA) & 24.722 & 25.516 \\
\hline $\mathrm{Kxx}(\% \mathrm{~B})$ & 50.956 & 50.829 \\
\hline
\end{tabular}

tal of total displacement since this last characteristic does not have a strong influence over the final added resistance in waves. The values can be confirmed through the Table 1.

The body plan of the model (fitted with fin keel and bulb) is on the Fig. 2 as well as a representation of the right hand coordinate system (bow up is positive) used in this work. The lines for both keels are represented on the Fig. 3.

\section{Experimental Condition}

The model was experimented in waves and still water fitted with a pole keel. The results for fin keel was obtained before and more details can be find on the references ${ }^{2) 3}$.

In the upright condition and still water, the velocity range corresponds to Froude number between 0.25 and 0.37, which encompass the velocity expected to be achieve on the upwind condition. When tested in still water, the velocity was kept constant for a Froude number equal to 0.30 , a constant wave height of $2.0 \%$ of waterline length and $\lambda / \mathrm{LWL}$ ranging from 0.75 to 2.5 with steps of 0.25 .

For the experiments done in heeled and yawed condition in still water, three velocities were chosen corresponding to Froude number $0.25,0.30$ and 0.35 . For each of them the following yaw angles were settled: $3.0,4.5$ and 6.0 degrees. Actually, the angles achieved differ from the initially settled ones due to autopilot limitations. However, those differences did not affect the data analysis.

For the heeled condition in waves three wave heights were experienced : $1.5 \%, 2.0 \%$ and $2.5 \%$ of length of waterline. The frequency range was similar to those ones in upright condition and the velocity corresponded to Froude number 0.30 .

The wave frequencies and heights were chosen following the considerations found at reference ${ }^{5 / 6)}$.

\section{Experimental Set-up}

Experiments were conducted at the towing tank of Yokohama National University that measures 100

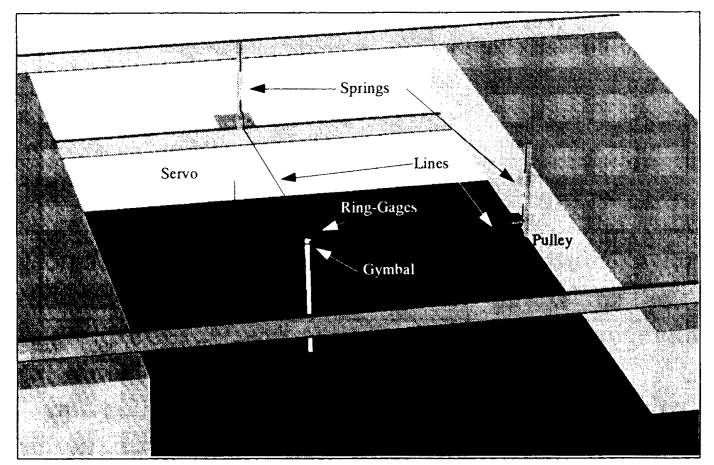

Fig. 4 Experimental arrangement. 
meter on length, being 8 meters wide and 3.5 meters deep. It is equipped with snake type wave generator and wave absorbers in both sides and in both extremities. Those wave absorbers could be raised whenever it was necessary. The carriage has a maximum speed of $2.4 \mathrm{~m} / \mathrm{s}$ and can be coupled with a sub-carriage in order to provide a wider work platform.

The experimental set-up is described in details for Hirayama at all ${ }^{3)}$ and a schematically rendering can be seen on Fig. 4. It is a free running set-up where the model is towed by two lines settled at a right angle and representing the resistance and the lateral force. Ring -gages were attached to this lines and measured the total force in the velocity direction and its perpendicular direction. The model was kept in its course through an auto pilot system that tracked two lamps on the deck by camera to determine the midship position and the yaw angle and send signals back to an active rudder through radio control.

When experienced in waves, springs were inserted to the lines in order to smooth the motions and allow a time history without discontinuity by snapping forces. The benefic consequence was that the values could be taken as an average over full cycles of period.

Servo-needle type wave probes installed in front of the carriage and in the position of model's midship acquired the wave height and encounter frequency.

Personal computers installed on the carriage were responsible for the data acquisition and storage as well as to control the autopilot and maintain the model in the pre settled yaw angle.

\section{Experimental Results}

\section{1 Upright Condition}

\section{1. 1 In Still Water}

The results in still water were compared with semiempirical results provided by Gerritsma ${ }^{7)}$ at all and Schlichting ${ }^{8)}$. Gerritsma ${ }^{7)}$ provided the equations for the calculation of canoe body resistance and

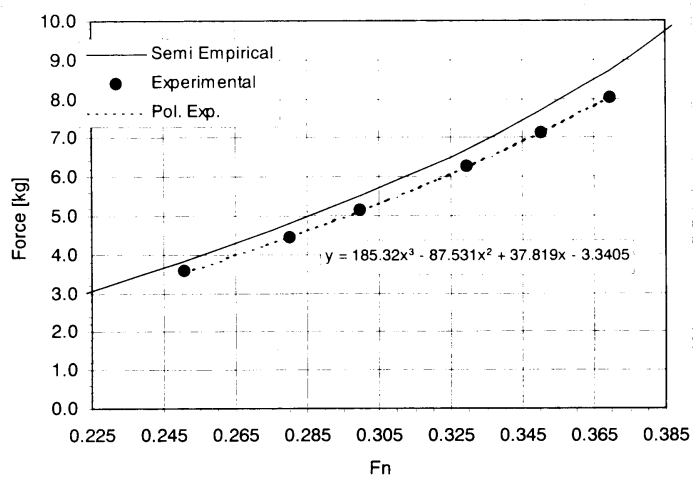

Fig. 5 Total resistance upright-Theoretical and experimental.
Schlichting ${ }^{8)}$ gave the drag coefficients for a cylinder and a sphere for the experienced Reynolds number. As it can be seen at the Fig. 5 , there is a very reasonable agreement between the two data. The experimental points seem to be shifted $5 \%$ down comparing with the semi-empirical ones. The semi-empirical curve was calculated using the drag coefficient for an infinite cylinder and for a sphere in an infinite fluid, did not accounting for interaction between them, which can be a reason for that bias. In order to help the visualization, the points were approximate by polynomial curves, called Pol. in the graphics.

It was important to do such a benchmark since the drag of the new appendages was very high and there were some doubts about the capacity of the ring-gage to measure accurately the total resistance of the model.

\subsubsection{In Waves}

The Fig. 6 and 7 presents the amplitude and phase of transfer function of pitch for both cases: hull fitted with fin keel and pole keel. Those data was obtained running the model upright against transient waves and, later, applying the Fast Fourier Transformation. This is a very efficient way to obtain the transfer function of

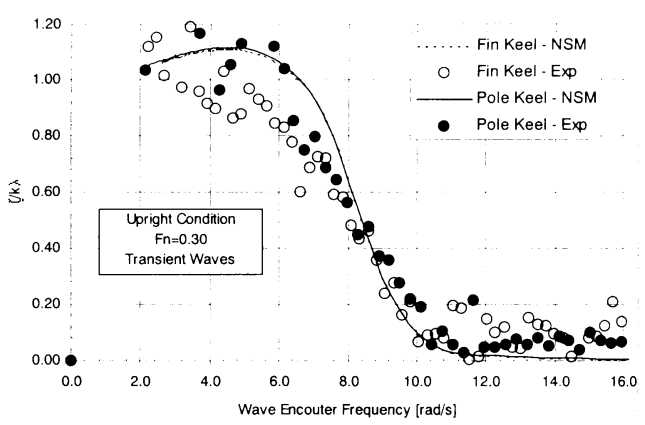

Fig. 6 Amplitude for the transfer function of pitch-Fin and pole keel-Upright.

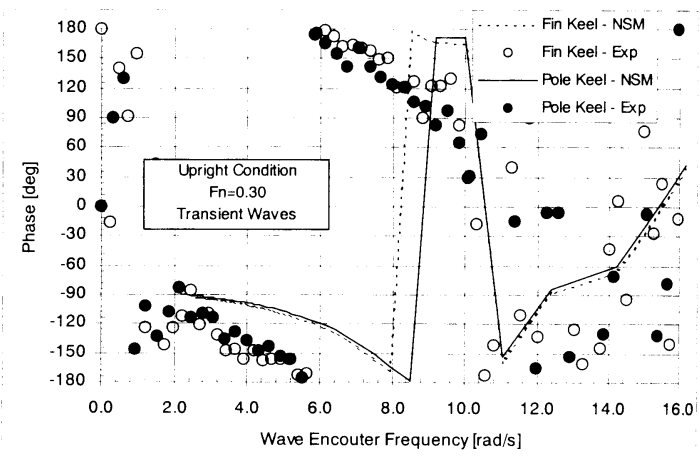

Fig. 7 Phase for the transfer function of pitch-Fin and keel-Upright. 
the model because only one run is necessary to obtain the motions in all frequencies of wave, as presented by Takezawa et all ${ }^{9110}$.

The amplitude of pitch (heave was not measured) was compared against the wave height measured by the front servo (and then, avoiding the interference by the waves generated by the model) and phase of motion was obtained using the wave slope measured by the servo located amidships.

It can be noticed that the amplitude results are pretty much similar, with the pole keel data fitting better the theoretical curve in the lower frequency range, while the results for fin keel presenting a value 20 to $25 \%$ lower than the NSM prediction. It reflects the bigger damping that the fin keel has comparing with the pole keel. The fact that the results for both kind of keels are very similar and that the New Strip Method was not able to model the appendices, lead to the conclusion that the motions of this yacht was predominantly dominated by its hull shape.

The phases angle for both keels are practically the same as can be seen in the Fig. 7. In the graphics, all the angles were shifted subtracting $180^{\circ}$ in order to correct the difference of definition of signs between the coordinate system fixed in the model (with the $z$ axis pointing downward) and the wave height (considered positive upwards).

The added resistance in waves divided by the wave height square is presented in the Fig. 8. The shape in both curves are almost the same, and it is very difficult to identify a trend that can point out undoubtedly the influence of keel over the added resistance in waves in the upright condition. The lower value of this component of resistance for the pole keel was not expected since the larger amplitude of pitch corresponds to a small damping as commented in the paragraph before. Such a difference can be due to other motions of the model, like heave, which also influence the added resistance in waves and is affected by the appendage geometry (as the horizontal projected area). Since by this time only pitch was measured, a full understanding of

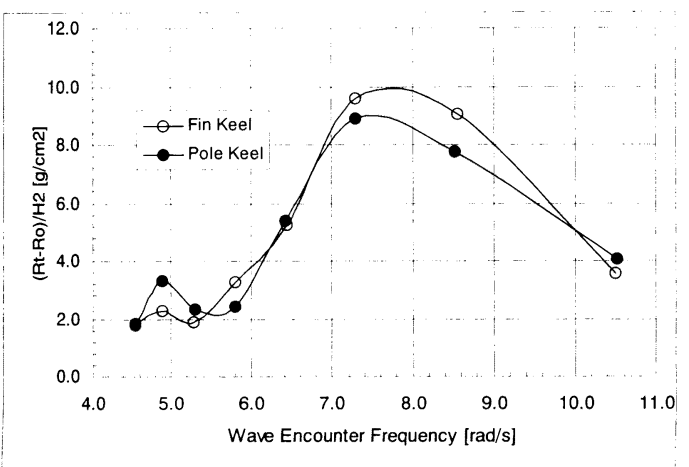

Fig. 8 Added resistance in waves-Pole keel and fin keel the mechanism of added resistance could not be achieved.

If the above conclusion can be extrapolated to the yacht itself and since the difference in added resistance in waves exists, factors as the frontal area of appendices and its geometrical distribution can influence not only the viscous resistance (pressure component) but also, the added resistance in waves in light wind conditions, when the yacht sail practically without heel.

\section{2 Heeled and Yawed Condition}

\section{2. 1 In Still Water}

The experiments conducted in still water with the model heeled and yawed were done in order to obtain the total resistance in this condition to subtract, further, from the total resistance in waves in the same situation and then, obtain the added resistance in waves.

Fig. 9 shows the total resistance of yacht for a combination of yaw $(\gamma)$ and heel $(\phi)$ angles and three velocities corresponding to Froude number of $0.25,0.30$ and 0 . 35. The trend of semi-empirical resistance (labeled $\mathrm{S}$. E. in the graphic) and experimental curves for velocities of 0.25 and 0.30 are very similar, being biased by the same $10 \%$ that was already detected in the upright condition. For the velocity of Froude number 0.35 it appears that the resistance increase with the increasing of $\left(\gamma \cos (\phi)^{2}\right)^{2}$, wich means that the resistance is increasing with the yaw and heel angle. Sincê the semi -empirical model evaluate the resistance due to the yaw (induced resistance) and due to the heel for the canoe body, and since the pole keel does not generated lift force (consequently there is no induced force), the increment of resistance reflected in the larger slope curve must came from the large angles of attack achieved by the rudder in order to provide larger yaw angles in that high velocity.

Since the pole keel is not a lift surface therefore does not presents circulation by orbital motion and the lateral force is just a component of drag in the perpendicular direction of center line, not so much attention was paid to the lateral force. It is presented here (Fig. 10) only as an extra data to confirm the semi-empirical previous calculation. It can be noticed that the slope of the curves differ in a small amout and when the velocity increase, the difference between the semi-empirical curve and the experimental one became bigger. This would be a reflection of the strong rudder action necessary to keep the model in the pre-determined yaw angle in high velocities. At the same time that the pole keel does not contribute to the directional estability, its large wake would disturb the flow over the rudder decreasing its efficiency. All in all, it results in large rudder angle and consequently an extra component of lateral force that was not accounted in the semi-empirical model.

One could argue that if the rudder has such a strong action, it would reflected in the final value of resistance as well. However, this does not affected the added 


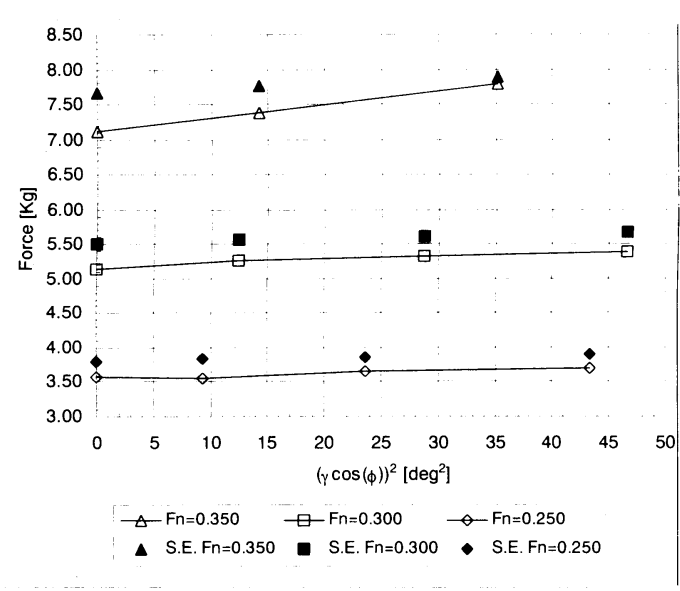

Fig. 9 Total resistance with pole keel-Heeled and yawed.

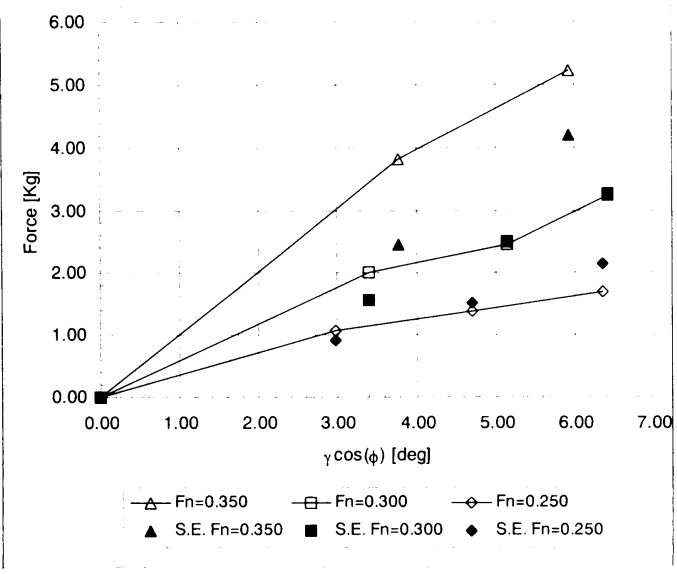

Fig. 10 Total lateral force with pole keel-Heeled and yawed.

resistance in waves since this action is found in both situations, still water and in waves, and the added resistance will be found by the subtraction of them. Of course the fluctuation of rudder angle in both cases is different, but the magnitude of values would differ in the order of $1 \%$ to $2 \%$. So, the resistance due to the attitude (wich include the rudder action) for both situations will be null for the sake of the calculation of added resistance in waves. In order to have an extra garantee of avoiding the rudder contribution to the total resistance, the added resistance in waves was obtained only for Froude number 0.30 . Fig. 10 shows that the experimental lateral force has a reasonable agreement with semi-empirical one for that velocity and, therefore does not presenting a strong rudder influence.

The values are plotted against $\gamma \cos \phi$, since it is expected the lateral force vary linearly with the attack angle. However, the smaller slope of the curves indicates that the lift generation is smaller than the theoretical prediction. The main underwater lift generator is the canoe body and it can be treated as a low aspect ratio lift surface, with strong cross-flow and, consequently, a non-linear relation for the lift-attack angle curve, which explain the appearance of data in the Fig. 10 .

\subsubsection{In Waves}

The apparatus developed at Yokohama National University was utilized once more to obtain the added resistance in waves, as well as the model motions, for the yacht in heeled and yawed condition, at this time fitted with the pole keel.

Fig. 11 and Fig. 12 represent the amplitude and phase of pitch respectively, for the fin keel and pole keel running in yawed and heeled condition for Froude number equal to 0.30 .

As in the upright condition, it can be noticed that the amplitude of transfer function of pitch for the model with pole keel fitted better the theoretical curve than the fin keel model. For this last one, in the wave frequencies ranging from 4.0 to $6.0 \mathrm{rad} / \mathrm{s}$, the difference between the experimental and theoretical transfer functions can reach orders of $37 \%$. The same does not happen with the pole keel, which points are located closer to the New Strip Method calculated curve. Once again become clear the bigger damping factor of cylinder and sphere over the pitch motion even more evident than in upright condition.

For the phase angle, once again the experimental results for fin and pole keel are practically the same. However, their values show a difference of phase with the theoretical one of around $90^{\circ}$.

The coefficient of added resistance in waves for the fin keel and pole keel is presented in the Fig. 13 beside their resistance in upright condition to facilitate the comparison. The values of added resistance in waves for the pole keel are surprising negatives, which means that the total resistance actually decreases when the yacht fitted with pole keel is beating the waves. The experiments were done twice for each wave frequencies and, for a pair of values with the same frequency, the results are quite similar so, the experimental results seem reliable. Also, the curve shows a clear decreasing tendency of added resistance in waves for the lower range of wave frequency.

It is not clear why such a result was obtained, and probably it can not be taken quantitatively. Some phenomena related with the double oscillation of cylinder (transversally and longitudinally) could imply in a reduction of overall drag coefficient of the appendage. It also could influence the lift generation by circulation of cylinder in heeled condition and as a consequence, to the total resistance, overshadowing the small increment in the added resistance in waves. However, it brings 


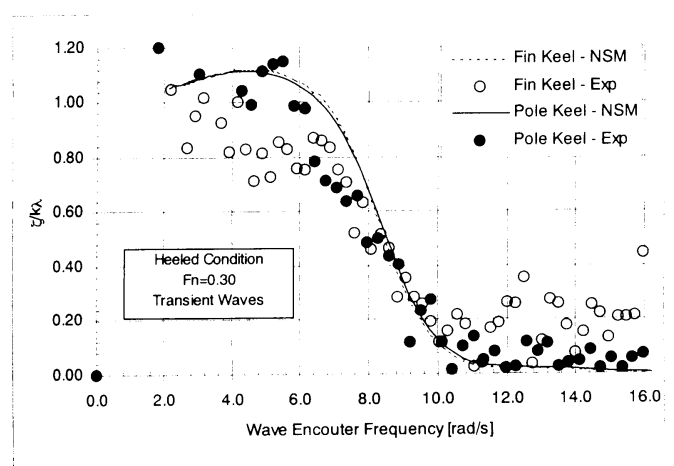

Fig. 11 Amplitude for the transfer function of pitch Fin and pole keel-Heeled and yawed.

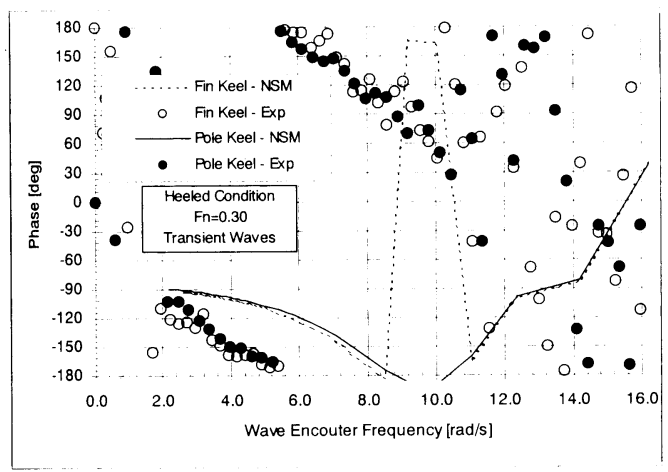

Fig. 12 Phase for the transfer function of pitch-Fin and pole keel-Heeled and yawed.

some interesting quantitative remarks, since it is evident that the keel plays an important factor over the added wave resistance.

\section{Additional result}

An interesting additional result was the determination of the resistance due to the attitude of the model.

The experiment in still water and upright condition was conducted once without any keel. The lack of directional stability occasioned strong and constant intervention from the rudder. If the velocity was increased, the rudder motion also became larger, increasing the total resistance of the model.

The Fig. 14 shows the semi-empirical calculation for the total resistance in still water for the canoe body and rudder (positioned at $0 \mathrm{o}$ ) and also the experimental results. The difference between the two curves can be attributed to the resistance due to the attitude of the model, which includes the rudder action, heeling motion and yawing motion.

\section{Conclusion}

The added resistance in waves in heeled and yawed

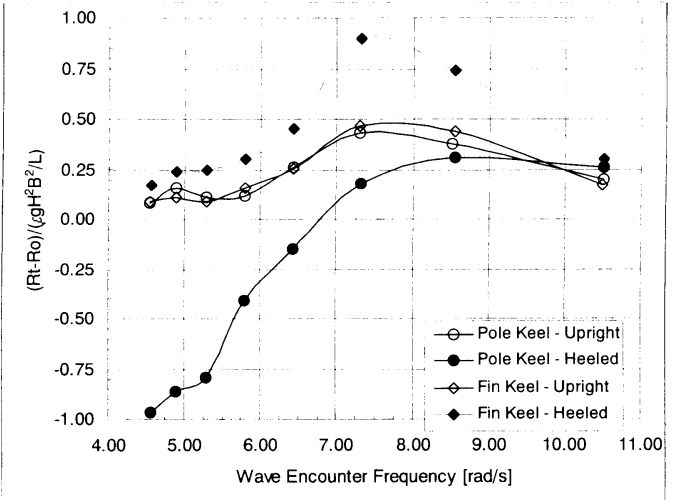

Fig. 13 Coefficient of added resistance in waves-Fin and pole keel-Upright and heeled.

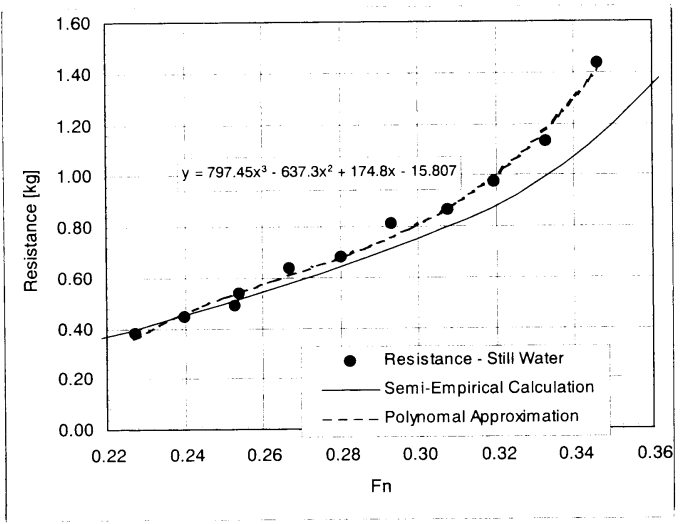

Fig. 14 Total resistance without keel.

condition was obtained for a hull fitted with a pole keel and its results were compared with similar model fitted with a fin keel. The following conclusions can be done:

1) The pitch of the model fitted with fin keel was very much reduced when compared with its pole keel counterpart. The difference between them could be as large as 37\%. Different frontal area and hydrodynamic form contribute to higher damping effect over the pitch motion.

2) For the even keel condition, such a difference reflected in the added wave resistance, lowering the total value of $\left(\mathrm{R}_{\mathrm{t}}-\mathrm{R}_{0}\right) / \mathrm{H}^{2}$ in the order of $10 \%$ for the pick region and being always smaller than the fin keel version in almost all the range of wave frequencies studied but the lower ones. The curves obtained show the same tendency and consistency along the entire range of frequencies.

3) In heeled and yawed condition some undesirable hydrodynamic phenomena generated by the pole keel interfered with the total resistance in waves, lowering its values and resulting in negative values for the added resistance in waves. The 
model was experienced twice in the same condition and the data analysis was done in the same manner that for the upright condition in order to confer reliability to the results. Meanwhile it is possible to conclude the influence of keel over the added resistance in this condition, since the strong tendency of the curve does not keep room for doubts about it.

4) However, more and better experiments must be done in order to obtain some quantitative results that corroborate the tendencies identified in this work and clarify the exactly reason why the added resistance in waves could be negative and determine if it is possible to achieve such a strong reduction with a conventional keel.

5) Another improvement that could help for determining the influence of appendages over the added resistance in waves would be adapt the set up in order to allow the measurements of heave motion and consequently obtain the model transfer function in that direction. Visual observation during the experiments, as well as a detailed analysis of geometry of appendages, suggest that motions in the vertical direction is also altered due to the change of keel and bulb. Larger horizontal area and differences in the geometry in the bulb (mainly) can result in different damping coefficient for heave, altering the spectrum of damping waves, the yacht motions and the added wave resistance. However, the research about heave is beyond the scope of this paper.

6) The experimental set - up developed by Hirayama at $\mathrm{all}^{2 / 3)}$ proved to be robust and also allow the determination of the resistance due to the attitude, a fundamental component of resistance for yachts that engages races that need many maneuvers, as during the windward leg of America's Cup race.

\section{Acknowledgement}

These researchers would like to express their gratitude to Mr. K. Miakawa and Mr. T. Takayama for their guidance and helping during the conducting of experiences. They also would like to extend their thanks to Mr. M Kayajima and all the students who carried the experiments at the Large Ocean Waves Towing Tank of Yokohama National University. Finally, they thank the Associate Prof. N. Mah who gave helpful guidance to students.

\section{References}

1) Marchaj, C. A., "Seaworthiness-The Forgotten Factor", Revised Edition, Tiller, St Michels USA, 1996.

2) Hirayama, T., Campos, M. P., "A New Experimental Trials for Obtaining the Added Resistance of Sailing Yacht", Journal of the Kansai Society of Naval Architects, Japan, No. 229,
March 1998.

3) Hirayama, T., Campos, M. P., "Improved Measuring Method for Added Wave Resistance of a Yawed and Heeled Sailing Yacht Model", Journal of Society of Naval Architects of Japan, Japan, Vol. 183, March 1998, p. 101-113.

4) Oossanen, P. Von, "Predicting the Speed of Sailing Yachts", SNAME Transactions, Vol. 101, 1993, p. 337-397.

5) Gerritsma, J., Keuning, J. A., "Performance of Light-and Heavy-Displacement Sailing Yachts in Waves", SNAME Marine Technology, Vol. 26, Jan. 1989 , p. 14 22 .

6) Gerritsma, J., Keuning, J. A., Versluis, A., "Sailing Yacht Performance in Calm Water and in Waves", The 11 th Chesapeake Sailing Yacht Symposium SNAME, Jan. 1993, p. 233-245.

7) Gerritsma, J.; O. R. ; Versluis, A., "Geometry, Resistance and Stability of the Delft Systematic Hull Series", International ShipBuilding Prog. ress, December 1981.

8) Schlichting, H., "Boundary Layer Theory", MacGraw-Hill, New York, 1968.

9) Takezawa, S.; Takekawa, M., “Advanced Experimental Techniques for Testing Models in Transient Water Waves-Part I-The Transient Test Technique on Ship Motions in Waves", The 11th Symposium on Naval Hydrodynamics, London, March and April 1976, p. 23-35.

10) Takezawa, S.; Hirayama, T., "Advanced Experimental Techniques for Testing Models in Transient Water Waves-Part II- The Controlled Transient Water Waves for Using in Shi Motion Tests", The 11th Symposium on Naval Hydrodynamics, London, March and April 1976, p. $37-54$.

11) Dean, R. G. ; Dalrymple, R. A., "Water Wave Mechanics for Engineers and Scientists", Second Edition, World Scientific Publishing Co. Pte. Ltd., London, 1991.

\section{Appendix}

The following graphics present the time history for two similar experiments in waves for the fin keel and pole keel in upright condition.

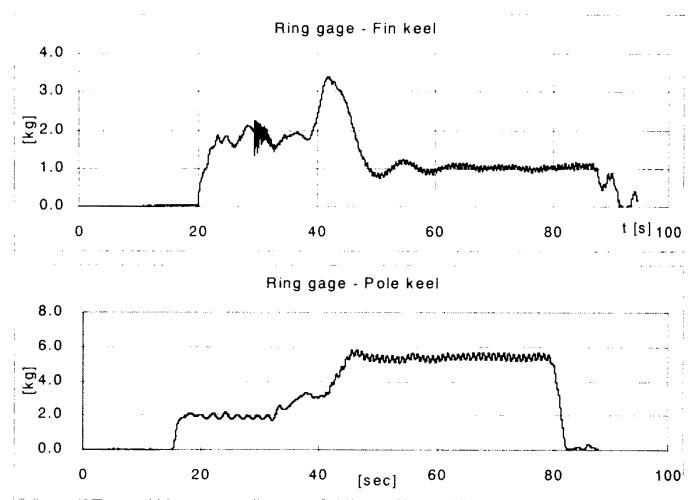

Fig. 15 Time history of resistance 


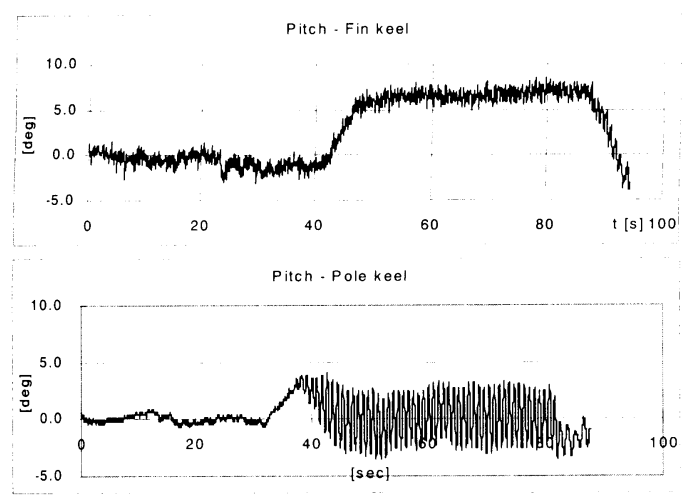

Fig. 16 Time history of pitch angle.

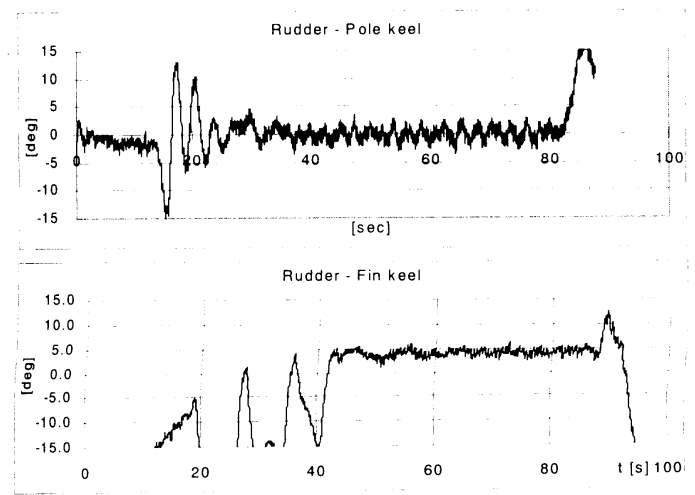

Fig. 17 Time history of rudder angle.

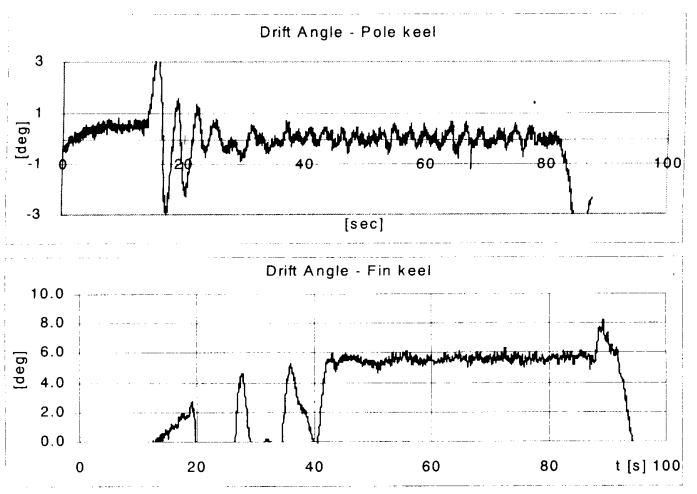

Fig. 18 Time history of drift angle. 